\title{
An experimental setup combining a highly sensitive detector for reaction products with a mass-selected cluster source and a low-temperature STM for advanced nanocatalysis measurements
}

\author{
S. Bonannia , K. Aït-Mansour, M. Hugentobler, H. Brune, and W. Harbich \\ Institute of Condensed Matter Physics (ICMP), École Polytechnique Fédérale de Lausanne (EPFL), 1015 Lausanne, Switzerland
}

Received 20 September 2010 / Received in final form 25 January 2011

Published online 28 June 2011 - (c) EDP Sciences, Società Italiana di Fisica, Springer-Verlag 2011

\begin{abstract}
We report on a home-built detector for catalytic reaction measurements offering good gas isolation from the surrounding ultrahigh vacuum components, high sensitivity for reaction products and a fast response time of $10 \mathrm{~ms}$ enabling dynamic studies correlated to reactant gas pulses. The device is mounted in ultrahigh vacuum and combined with a low-temperature scanning tunneling microscope and a source for the deposition of mass-selected clusters. This combination allows for a direct correlation between surface morphology and catalytic properties of model catalysts. The performances of the new detector are illustrated by measurements on two model systems. Thermal desorption spectroscopy of CO carried out on morphologically well characterized $\mathrm{Pt}$ on $\mathrm{TiO}_{2}(110)-(1 \times 1)$ reveals several desorption features, which can be attributed to different surface sites. Catalytic $\mathrm{CO}$ oxidation performed by alternatingly pulsing isotopic $\mathrm{CO}$ and $\mathrm{O}_{2}$ on a $\mathrm{Pt}$ film on yttria stabilized zirconia reveals the $\mathrm{CO}$ or $\mathrm{O}$ rich temperature regimes. The $\mathrm{CO}_{2}$ production rate correlated with either one of the reactants can perfectly be reproduced by a kinetic reaction model giving access to the respective adsorption energies.
\end{abstract}

\section{Introduction}

Catalytic activity measurements of small size-selected clusters supported on $\mathrm{MgO}$ have been pioneered by Heiz et al. [1-3] and have initiated considerable experimental and theoretical effort to study the catalytic properties of model catalysts based on size-selected oxide-supported metal nanoclusters [4-18]. Since the first instrument by Heiz et al. [19], further rather complex setups have been developed, allowing, for instance, deposition of massselected clusters in ultrahigh vacuum (UHV) environment and in-situ catalytic activity measurements based on temperature-programmed reaction (TPR) [13,20-23]. Other instruments including the one in our group focused on the morphology and stability studies of mass-selected clusters on well defined substrates [16,24-28]. However, one of the key open issues has remained the correlation of the chemical cluster activity with their morphology, ideally before and after the reaction has taken place. Instruments devoted to this question have been developed rather recently. Kemper et al. have combined variabletemperature scanning tunneling microscopy (STM) with thermal desorption spectroscopy (TDS) to study massselected clusters deposited in UHV on semiconductor surfaces [29]. Very recently, a sophisticated experimental setup has been realized by Watanabe and Isomura [30],

\footnotetext{
a e-mail: simon.bonanni@epfl.ch
}

which has the advantage of in-situ morphology characterization of supported size-selected clusters by low temperature (LT) STM in addition to in-situ (high pressure) chemical reaction measurements.

In this paper, we present a UHV setup combining deposition of mass-selected clusters, a home-built LT-STM for the in situ characterization of morphology and electronic properties, and a new home-built device enabling dynamic reactivity studies on surfaces with very small amounts of catalytically active material; we call this device "sniffer". In the following we briefly describe the preexisting parts, i.e., cluster source and LT-STM, and then focus on the newly developed sniffer. Besides standard measurements like TDS or TPR, the sniffer allows to expose the sample to gas pulses of well defined pressure and duration and to measure at the same time the reaction products from the sample, and this as function of the sample temperature. Experimental results on $\mathrm{Pt} / \mathrm{TiO}_{2}(110)$ $(1 \times 1)$ and $\mathrm{Pt}$ on a standard ion conductor, yttria stabilized zirconia (YSZ), illustrate the operation and the performance of this device.

\section{Experimental setup}

\subsection{Overview}

A simplified diagram of the experimental setup is shown in Figure 1. The apparatus is composed of three chambers 


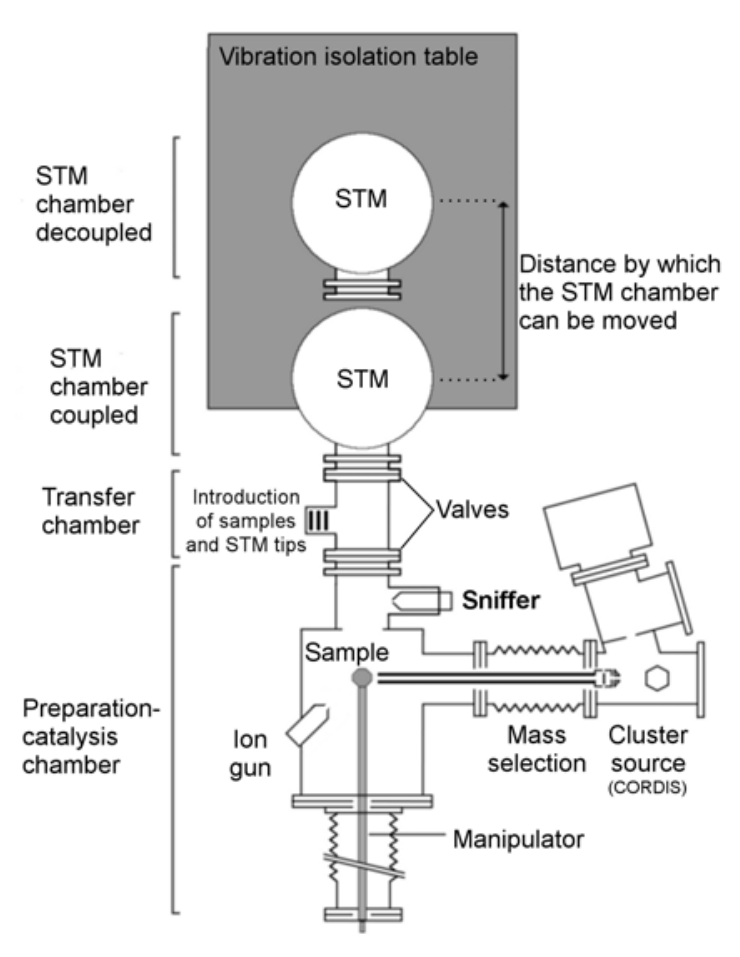

Fig. 1. Diagram of the UHV setup composed of three chambers. The preparation-catalysis chamber is equipped with standard facilities for surface preparation, the source for deposition of mass-selected clusters, and the sniffer, see Figure 2. It is connected to the STM chamber through the transfer chamber, also allowing the introduction of samples and STM tips through a load-lock. The cryogenic manipulator permits sample transfer between all three chambers under UHV and at low temperature.

independently pumped and separated by UHV gate valves. The main chamber in the lower part of this figure is devoted to sample preparation and catalysis, while the upper chamber serves for STM investigations and can be separated from the remaining UHV system for vibrational and acoustic decoupling. The two chambers are connected through a transfer chamber, where new samples and STM tips are introduced and transferred between both chambers. The base pressure is in the low $10^{-11}$ mbar range in the STM chamber and in the low $10^{-10}$ mbar range in the two other chambers. The pressure in the preparation-catalysis chamber can be further reduced to the $10^{-11}$ mbar range using a liquid nitrogen cooled cryogenic trap.

The preparation-catalysis chamber contains standard surface preparation techniques such as a sputter gun and a sample manipulator enabling sample heating by electronbombardment as well as cooling to $30 \mathrm{~K}$ by liquid $\mathrm{He}$ and to $90 \mathrm{~K}$ by liquid $\mathrm{N}_{2}$, see reference [25] for details. Further, it includes a facility for the deposition of sizeselected metal clusters which is described in detail elsewhere [25,31], as well as the new home-built instrument for catalytic studies (sniffer), which will be presented in the next section. The manipulator has sufficient linear travel

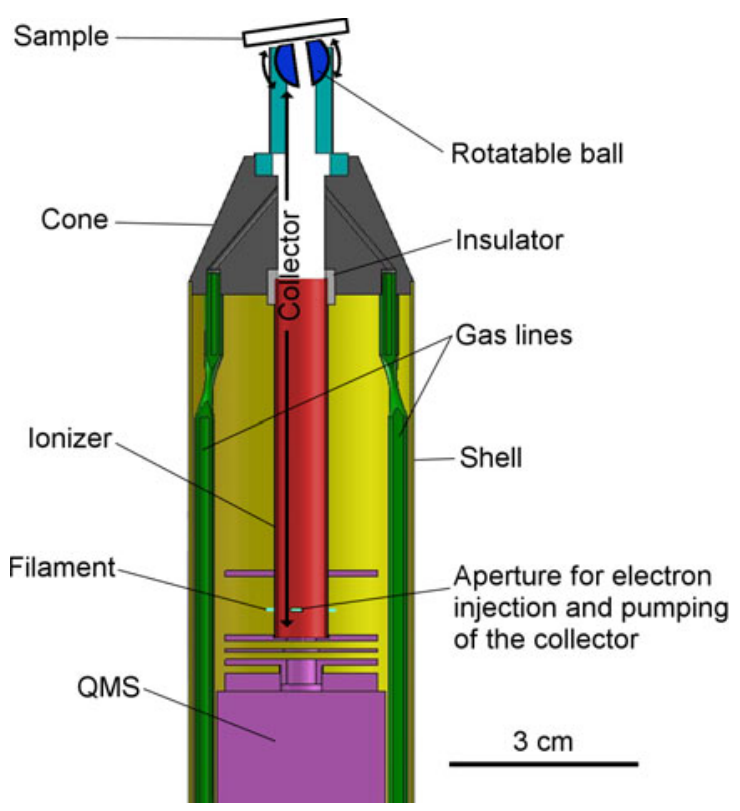

Fig. 2. (Color online) Schematic drawing of the sniffer.

to allow sample transfer between the two main chambers under UHV and cryogenic conditions.

The home-made LT-STM permits measurements at sample temperatures reaching $5 \mathrm{~K}$ by cooling with liquid helium, but usually the measurements are done at $80 \mathrm{~K}$ using liquid nitrogen. The STM head has been modified with respect to the description given in reference [25]. As described in more detail in reference [32], the coarse approach of the tip now consists of a linear piezoelectric motor inspired by the one of Pan et al. [33,34]. The main advantages are the large $z$-travel making sample transfer easier and the enhanced thermal contact between the cryostat and the sample.

\subsection{Sniffer}

The main idea in the design of the home-built sniffer (Fig. 2) is the possibility of creating an almost independent differentially pumped volume, which allows the use of rather high gas pressures. The gases desorbing from the sample get trapped in this volume labeled collector in Figure 2 and are continuously analyzed by means of an integrated quadrupole mass spectrometer (QMS, Prisma QMS 200 Pfeiffer-Vacuum) shown in purple in Figure 2. In order to integrate the commercial QMS in the sniffer, the ionization cage of the open ion source has been substituted by a $8.9 \mathrm{~mm}$ diameter stainless steel cylindrical tube. This tube is labeled ionizer and shown in red in Figure 2. It represents the main volume of the collector.

A hot yttrium filament (schematized with a line in Fig. 2) is positioned outside the ionizer tube and near a $1 \mathrm{~mm} \times 3 \mathrm{~mm}$ aperture in the tube. It produces electrons that are accelerated through the aperture into the ionizer by a $100 \mathrm{~V}$ potential. The aperture also serves to pump the collector. The electrons ionize the gas, and a system of electrostatic lenses guides the ions through a $1 \mathrm{~mm}^{2}$ hole into the quadrupole, where the mass analysis 
is performed. Placing the filament outside the ionizer reduces the catalytic background signal produced by the reactions taking place on the hot filament. The sniffer parts described above are enclosed in a stainless steel shell (yellow in Fig. 2) differentially pumped by a turbomolecular pump. The base pressure in the differential pumping line of the sniffer is below $2 \times 10^{-9}$ mbar.

The injection of well defined amounts of gases in the collector is controlled by two UHV compatible electromagnetic pulsed valves (Sensortechnics, model 099-0340-900), positioned below the part of the sniffer shown in Figure 2. The cone in dark grey contains a portion of the collector volume. It also allows the gas lines to converge with a " $\Lambda$ " shape to the principal axis of the collector. The gas tightness and electrical insulation between the cone and the ionizer is guaranteed by a Teflon ring (insulator in Fig. 2).

Since the two electromagnetic valves can be controlled independently, the sniffer allows to perform catalytic reaction measurements in different ways. For instance, it is possible to study:

- The evolution of the reaction products as a function of the partial pressure of two dosed reactants and the sample temperature.

- The reaction between two reactants by keeping a constant pressure of one reactant (high frequency of gas pulses) and pulsing the other with a chosen (much smaller) frequency.

- The reaction dynamics by pulsing both reactants with a delay to each other (see below).

The gas isolation and the selectivity with which one captures the reactants and the dosed gases coming off the sample, and not the ones desorbing from other parts of the vacuum chamber, crucially depend on the distance between the sample and the sniffer end. Since the manipulator has rotation around its axis as only angular degree of freedom, parallelism of the sniffer entrance and the sample surface has been insured by a stainless steel ball (blue in Fig. 2) mounted at the end of the collector, where it can freely rotate. The ball has a central bore of $3 \mathrm{~mm}$. The ball apex facing the sample has a planar part perpendicular to the bore which can be oriented parallel to the sample surface by gently touching it. Afterwards, the sample is retracted until the electrical contact between ball and sample is ruptured. The smallest distance obtainable this way is given by the mechanical stability of the long manipulator arm perpendicular to its axis. We achieve $1 / 10 \mathrm{~mm}$, reducing the gas exchange between preparation chamber and collector by a factor of at least 10 with respect to the configuration with the sample far from the sniffer. The reduced gas conductance between sniffer and preparation chamber together with the differential pumping of the sniffer allow to keep a static pressure difference of three orders of magnitude between the preparation chamber and the sniffer collector while dosing gases. In addition, it enables higher exposing gas pressures compared to a more open solution.

The theoretical time constant of the collector, when the entrance of the sniffer is firmly connected with the
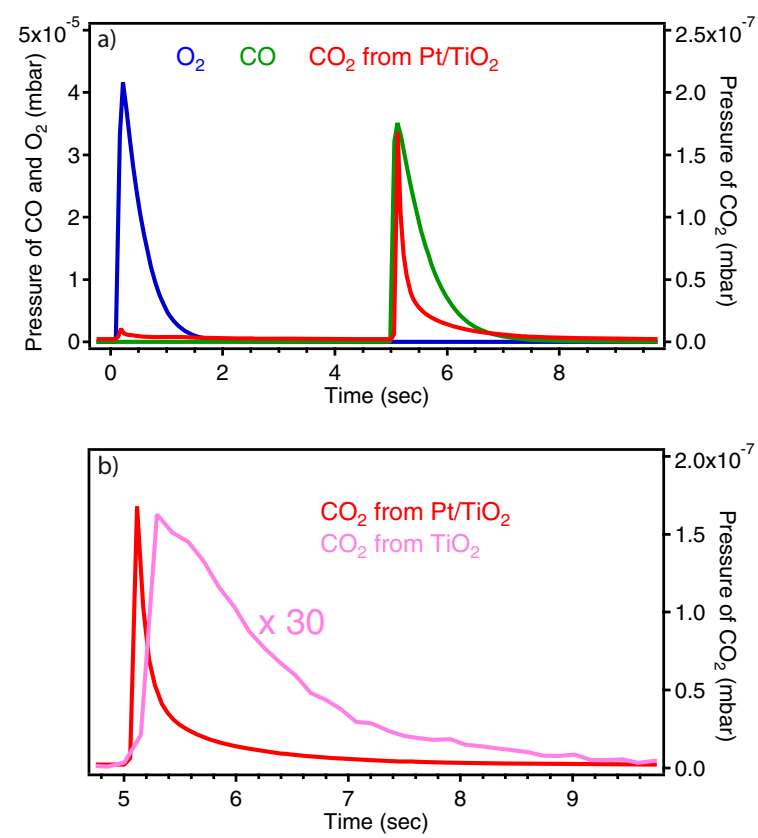

Fig. 3. (Color online) (a) Partial pressure evolution inside the collector of the reactants ( $\mathrm{CO}$ in green and $\mathrm{O}_{2}$ in blue) and the product $\left(\mathrm{CO}_{2}\right.$ in red), coming off a $\mathrm{Pt} / \mathrm{TiO}_{2}(110)$ sample held at $480 \mathrm{~K}$ during a typical catalytic activity measurement. (b) Comparison between the $\mathrm{CO}_{2}$ productions synchronized with $\mathrm{CO}$ pulses from $\mathrm{Pt} / \mathrm{TiO}_{2}(110)$ (in red, same as in (a)) and clean $\mathrm{TiO}_{2}(110)$ (in pink). The intensity of the $\mathrm{CO}_{2}$ signal obtained on the clean $\mathrm{TiO}_{2}(110)$ surface has been multiplied by a factor 30 .

sample surface, can be estimated by considering the ratio between the volume of the collector and the gas pumping speed through both the aperture for electron injection and the hole for ion injection into the quadrupole. This yields $10 \mathrm{~ms}$. In order to estimate the real temporal behavior of the sniffer we consider catalytic oxidation measurement of $\mathrm{CO}$ on $\mathrm{Pt}$ nanoclusters on $\mathrm{TiO}_{2}(110)$ [35] performed by pulsing $\mathrm{O}_{2}$ and $\mathrm{CO}$ with a delay of $5 \mathrm{~s}$. As can be seen in Figure 3a, where 20 Langmuir ( 1 Langmuir $=1.33 \times$ $10^{-6}$ mbar $\left.\times 1 \mathrm{~s}\right) \mathrm{CO}$ and $\mathrm{O}_{2}$ pulses are shown, the time profiles of the reactants are comparatively large and mainly given by the conductance of the gas lines from the pulsed valves to the sample. The onset times are $130 \mathrm{~ms}$ for both gases, while the full width at half maximum is $550 \mathrm{~ms}$ for $\mathrm{CO}$ and $450 \mathrm{~ms}$ for $\mathrm{O}_{2}$. The temporal decay after the maximum can be fitted for $\mathrm{CO}$ and $\mathrm{O}_{2}$ by a single exponential, each yielding the time constants $\tau_{\mathrm{CO}}=550 \mathrm{~ms}$ and $\tau_{\mathrm{O}_{2}}=380 \mathrm{~ms}$. The time constant of the reaction product $\left(\mathrm{CO}_{2}\right)$ is markedly shorter. The tail of the peak synchronized with the $\mathrm{CO}$ pulse can be fitted with a double exponential yielding $\tau_{\mathrm{CO}_{2}, 1}=80 \mathrm{~ms}$ for the main component (amplitude $1.21 \times 10^{-7}$ mbar) and $\tau_{\mathrm{CO}_{2}, 2}=620 \mathrm{~ms}$ for the smaller component (amplitude $4.3 \times 10^{-8} \mathrm{mbar}$ ). Subtracting the acquisition time of the spectrometer of $65 \mathrm{~ms}$, we find that the main component of $\mathrm{CO}_{2}$ has a time constant of $15 \mathrm{~ms}$, very close to the theoretical value of $10 \mathrm{~ms}$ estimated before. The fact that the time constant 
of this reaction comes close to the theoretical limit of the time resolution of our instrument can be explained by the fact that the main $\mathrm{CO}_{2}$ component corresponds to the reaction product created instantly into the collector as soon as the first $\mathrm{CO}$ molecules arrive at the oxygen pre-covered surface. The second component is caused by the continued flux of CO even after the valves have been closed due to the finite conductance of the gas supply and due to the finite pump speed. In Figure $3 \mathrm{~b}$ the $\mathrm{CO}_{2}$ production on the active $\mathrm{Pt} / \mathrm{TiO}_{2}$ surface is compared with the background $\mathrm{CO}_{2}$ production on a clean $\mathrm{TiO}_{2}$ surface. The latter is attributed to the background catalytic reaction taking place on the various parts of the sniffer. This background peak is 30 times smaller and 10 times wider than the one from the $\mathrm{Pt} / \mathrm{TiO}_{2}$ surface, allowing straightforward discrimination of signal and background.

The sniffer permits also to carry out TDS or TPR measurements by dosing gases onto the sample at low temperatures and measuring either the initial species (TDS) or the reaction products (TPR) as function of increasing temperature. TDS performed with this new design shows two main advantages with respect to TDS measured with standard QMS-based instruments. First, the gases desorbing from the sample stagnate in the collector due to the small pump rate, and therefore the partial pressure in the collector increases to values easily detectable by the QMS even for a very small flux of molecules. The white noise level of our detector corresponds to a desorption rate from the sample of $2 \times 10^{10}$ molecules $/\left(\mathrm{cm}^{2} \mathrm{~s}\right)$ for the mass $47\left({ }^{13} \mathrm{C}^{16} \mathrm{O}^{18} \mathrm{O}\right)$. Second, since the gases are dosed only locally on the sample, the pollution of the preparation chamber by these gases is negligible, and thus the measured TD spectra are almost completely free of parasite peaks of gases desorbing, e.g., from the sample holder or the filament during heating.

For a quantitative analysis of the data measured by the sniffer in terms of number of gas molecules coming on and off the sample per unit of time and surface, two calibrations have been performed. (i) We determined the relation between the partial pressure in the sniffer and the measured ion current, which is used to calculate the amount of the dosed gas. (ii) We established the relation between the flux of molecules entering in the sniffer and the measured ion current, which is used for a quantitative analysis of the gas desorbing from the sample. For calibration (i) no sample was positioned in front of the sniffer, the differential pumping of the sniffer was closed by a valve, and argon was introduced in the preparation chamber and its partial pressure was increased step by step. This way the sniffer was only pumped via the preparation chamber and thus the argon pressure in the sniffer was the same as the one in the preparation chamber, which has continuously been monitored by a gauge. The ion current corresponding to each argon pressure step was then measured. For calibration (ii) the sniffer was in the usual measurement configuration, i.e., it was differentially pumped and the sample was positioned in front of it, so that the gas exchange between the sniffer and the preparation chamber was minimized. We performed TDS measurements of
$\mathrm{CO}$ and $\mathrm{H}_{2} \mathrm{O}$ on $\mathrm{TiO}_{2}(110)-(1 \times 1)$ and the integrals of the desorption peaks of both molecules have been determined and compared to those found in literature [36-39].

\section{Results and discussion}

\subsection{Surface morphology of $\mathrm{Pt} / \mathrm{TiO}_{2}(110)$}

In order to demonstrate the performance of the LTSTM we show in Figure 4 measurements at $80 \mathrm{~K}$ on $\mathrm{Pt} / \mathrm{TiO}_{2}(110)-(1 \times 1)$. The STM has been attached to the rest of the machine during these measurements. As pointed out above, the $\mathrm{z}$ peak-to-peak noise can be improved by decoupling it, therefore the present results show the case of non-optimized vibration isolation. The STM images have been measured in the constant-current mode at $V_{t}=+1.5 \mathrm{~V}$ and $I_{t}=0.1 \mathrm{nA}$, the stated voltage refers to the electric potential of the sample with respect to the tip. The tip has been prepared from an electrochemically etched tungsten wire. The STM images have been processed with the WSxM software [40]. A rutile $\mathrm{TiO}_{2}(110)$ single-crystal from MTI Corporation has been used as substrate. The $\mathrm{TiO}_{2}(110)-(1 \times 1)$ surface has been prepared by repeated cycles of Ar-ion sputtering (150 nA, $1 \mathrm{kV}$, ten hours) at room temperature (RT) followed by annealing at $1100 \mathrm{~K}$ for one hour. It is well known that sputterannealing cycles reduce the $\mathrm{TiO}_{2}(110)$ crystal by producing point defects, such as bulk $\mathrm{Ti}^{3+}$ interstitials as well as bulk and surface $\mathrm{O}$ vacancies $\left(\mathrm{O}_{v a c}\right)$. These defects introduce electronic states in the $\mathrm{TiO}_{2}$ band gap, which makes STM measurements possible [41-43].

Figure 4a shows an STM image of the clean $\mathrm{TiO}_{2}(110)$ $(1 \times 1)$ surface with two adjacent terraces. The typical terrace width has been determined from large scale images to $40 \mathrm{~nm}$. The terraces are separated by a monatomic step appearing with a height of $3.2 \pm 0.1 \AA$, which agrees well with the value expected from the rutile crystal structure $(3.24 \AA)$. The observed atomic contrast is well known to be dominated by electronic effects and the bright and dark lines correspond to the [001]-oriented rows of fivefold coordinated $\mathrm{Ti}$ and bridging $\mathrm{O}$ atoms, respectively [41]. A number of point defects are also seen, which are mostly $\mathrm{O}_{v a c}$ and some hydroxyls $(\mathrm{OH})$, the latter resulting from the dissociation of residual water molecules at $\mathrm{O}_{\text {vac }}$ sites [44-46]. Both defects are discerned by the apparent height of $0.3 \pm 0.1 \AA\left(\mathrm{O}_{v a c}\right)$ and $0.6 \pm 0.1 \AA(\mathrm{OH})$ with respect to the $\mathrm{O}$ rows. The $\mathrm{O}_{\text {vac }}$ density estimated from Figure $4 \mathrm{a}$ is $5.4 \%$ monolayer (ML), where $1 \mathrm{ML}$ is defined as the density of unit cells of the $\mathrm{TiO}_{2}(110)-(1 \times 1)$ surface, i.e., $5.2 \times 10^{14} \mathrm{~cm}^{-2}$. This $\mathrm{O}_{\text {vac }}$ concentration is comparable to those found in former studies for reduced crystals [41-47].

$\mathrm{Pt}_{1}^{+}$has been deposited with a kinetic energy of $7 \mathrm{eV}$ by means of the mass-selected cluster source on the clean $\mathrm{TiO}_{2}(110)-(1 \times 1)$ surface kept at RT. The deposited Pt coverage was about $25 \% \mathrm{ML}$, where one ML Pt refers to the $\mathrm{Pt}(111)$ atomic density of $1.50 \times 10^{15}$ atoms $/ \mathrm{cm}^{2}$. This coverage has been determined by the ion current $(2.0 \mathrm{nA})$, the exposure time $(130 \mathrm{~min})$ and sample 

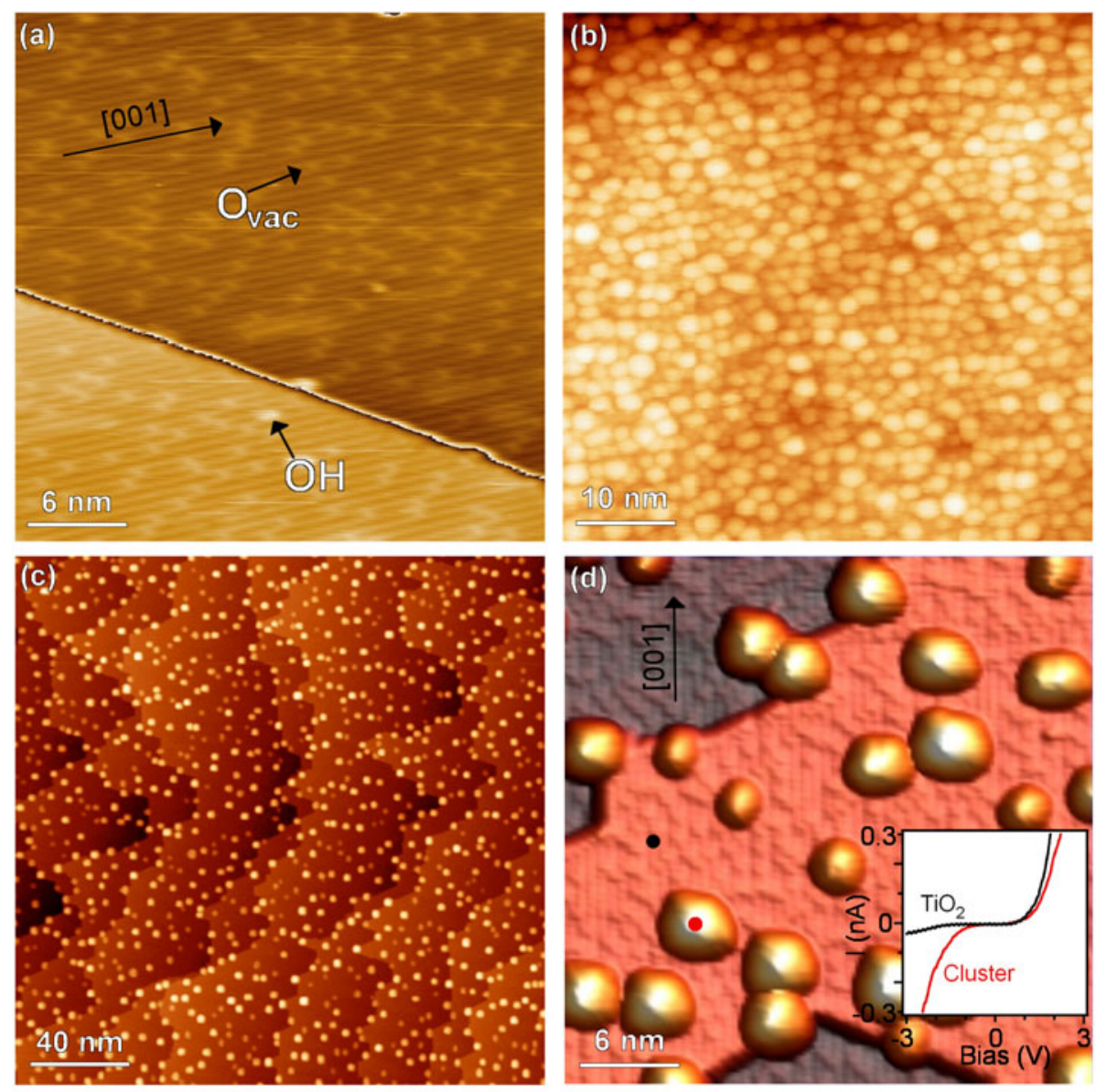

Fig. 4. (Color online) Constant current STM images of (a) clean $\mathrm{TiO}_{2}(110)-(1 \times 1)$ and $(\mathrm{b}-\mathrm{d})$ with the presence of $\mathrm{Pt}\left(V_{t}=1.5 \mathrm{~V}\right.$, $I_{t}=100 \mathrm{pA}, T=80 \mathrm{~K}$ for all images). (a) The clean surface shows bright and dark lines attributed to [001]-oriented Ti and $\mathrm{O}$ rows, respectively. Bright spots on the oxygen lines, shown by arrows, are attributed to $\mathrm{O}_{\text {vac }}$ and $\mathrm{OH}$, with $\mathrm{OH}$ appearing brighter than $\mathrm{O}_{v a c}$. The height difference due to the $\mathrm{TiO}_{2}(110)$ step has been subtracted in order to enhance the contrast related to the atomic features on the bare terraces. (b) After deposition of $25 \% \mathrm{ML}$ Pt on the substrate held at RT. (c, d) After annealing of the sample shown in (b) at $1100 \mathrm{~K}$ during three hours: (c) overview and (d) close-up. The inset in (d) shows $I(V)$ characteristics on the two positions shown by black and red spots in the STM image (d): red curve on a cluster and black curve on the $\mathrm{TiO}_{2}$ substrate. The setpoint for tip stabilization in the $I(V)$ spectra is the same as for the topographic image.

surface $\left(0.25 \mathrm{~cm}^{2}\right)$. Figure $4 \mathrm{~b}$ shows the morphology of the sample after $\mathrm{Pt}$ deposition. It is seen that clusters with apparent heights ranging from 3 to $6 \AA$ form on $\mathrm{TiO}_{2}(110)$ and largely hide the substrate features, although some substrate step edges can be recognized (e.g., left upper corner in Fig. 4b). Due to the tip convolution the $\mathrm{TiO}_{2}(110)$ surface appears as almost fully covered by $\mathrm{Pt}$, which is not the case as demonstrated below by TDS of CO.

Annealing the sample at $1100 \mathrm{~K}$ for three hours gives rise to the morphology shown in the STM images of Figures $4 \mathrm{c}$ and $4 \mathrm{~d}$, where one can clearly observe that larger clusters have formed on the bare terraces as well as at the steps of the $\mathrm{TiO}_{2}(110)$ surface. The average apparent cluster height is found to be $10.0 \AA$ and the cluster density is $2.7 \times 10^{12} \mathrm{~cm}^{-2}$. The overview image (Fig. 4c), as well as other images taken of this sample, reveal that the sample morphology is quite homogenous such that spatially integrating mass-spectroscopy measurements can be attributed to the shown morphology. $\mathrm{Pt} / \mathrm{TiO}_{2}$ is known as a "strong metal-support interaction" (SMSI) system, which, annealed above $700 \mathrm{~K}$, results in the encapsulation of the metal clusters by a titania thin layer coming from the support $[48,49]$. Assuming a half-spherical shape for the clusters, one can estimate their volume containing an equivalent $\mathrm{Pt}$ amount of $35 \% \mathrm{ML}$, again with respect to the $\mathrm{Pt}(111)$ atomic density. This rough estimate is in agreement with the deposited amount of $\mathrm{Pt}$, but it leaves some space for the Pt clusters being covered by a thin titania layer which is expected to slightly increase their apparent height [50]. The inset in Figure 4d shows $I(V)$ curves revealing a clear difference between the cluster (red curve) and the $\mathrm{TiO}_{2}$ substrate (black curve). From these measurements, the gap of the reduced $\mathrm{TiO}_{2}$ can be estimated to about $2.4 \mathrm{eV}$ which agrees with the value of $2.3 \mathrm{eV}$ obtained by other measurements [51], whereas the gap measured on the cluster is significantly smaller. 


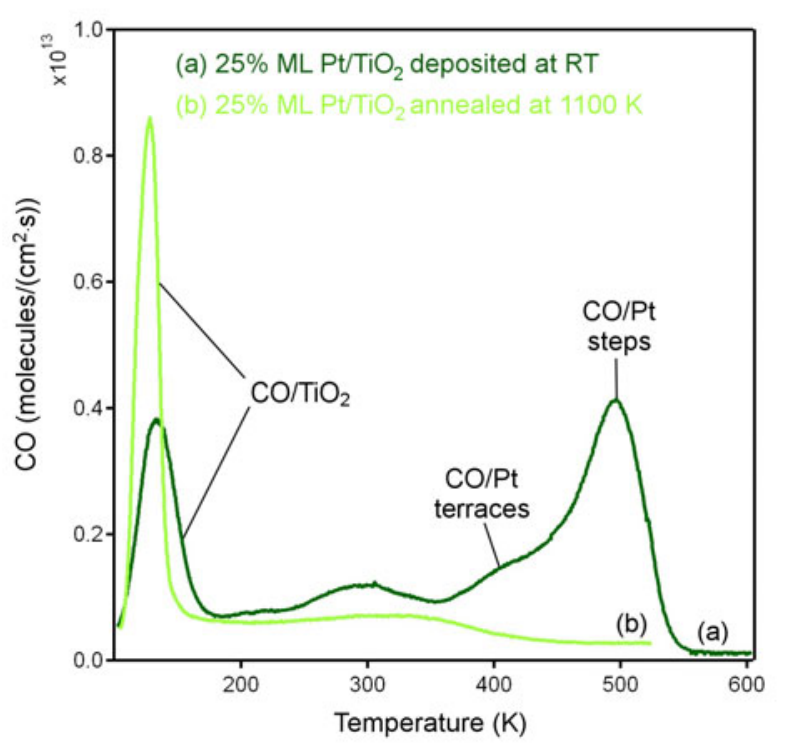

Fig. 5. (Color online) TDS measurements after CO saturation at $100 \mathrm{~K}$ of $25 \% \mathrm{ML} \mathrm{Pt} / \mathrm{TiO}_{2}(110)-(1 \times 1)$ deposited at RT before (a) and after (b) annealing at $1100 \mathrm{~K}$. The heating rate in TDS is $1 \mathrm{~K} / \mathrm{s}$. In (a), two principal peaks are observed, one at about $150 \mathrm{~K}$ attributed to $\mathrm{CO}$ desorbing from the $\mathrm{TiO}_{2}$ substrate and the other at about $500 \mathrm{~K}$ attributed to $\mathrm{CO}$ desorbing from Pt steps. There is also a shoulder at about $400 \mathrm{~K}$ attributed to $\mathrm{CO}$ desorbing from $\mathrm{Pt}$ terraces, and an additional peak is observed at about $300 \mathrm{~K}$. In (b), the peak at about $150 \mathrm{~K}$ results from $\mathrm{CO}$ desorption from $\mathrm{TiO}_{2}$, as in (a).

However, the clusters still show a nonmetallic behavior, probably due to their encapsulation by a titania layer.

\subsection{TDS measurements of $\mathrm{CO}$ on $\mathrm{Pt} / \mathrm{TiO}_{2}$}

Figure 5 shows TDS measurements performed with the sniffer after $\mathrm{CO}$ saturation at $100 \mathrm{~K}$ of the samples shown in Figure $4 \mathrm{~b}-4 \mathrm{~d}$, i.e., $25 \% \mathrm{ML} \mathrm{Pt} / \mathrm{TiO}_{2}$ at $\mathrm{RT}$ before and after annealing at $1100 \mathrm{~K}$ (spectra (a) and (b), respectively, in Fig. 5). In both TD spectra, a desorption peak at about $150 \mathrm{~K}$ is seen. In agreement with the literature, this peak is attributed to $\mathrm{CO}$ desorbing from the $\mathrm{TiO}_{2}$ substrate $[39,52]$. The peak intensity is much lower before annealing since the substrate area covered by $\mathrm{Pt}$ is higher. Spectrum (a) shows another clear desorption peak at about $500 \mathrm{~K}$ with a shoulder at about $400 \mathrm{~K}$. In comparison with literature, these two features may be attributed to $\mathrm{CO}$ desorbing from $\mathrm{Pt}$ steps and terraces, respectively [53,54]. The formation of $\mathrm{Pt}$ terraces is possible due to ripening during the annealing ramp of the TDS measurement. Another peak is observed in spectrum (a) at $300 \mathrm{~K}$. As the temperature of this peak is in-between those of $\mathrm{CO}$ on $\mathrm{TiO}_{2}$ and $\mathrm{Pt}$, we attribute this peak to $\mathrm{CO}$ desorbing from $\mathrm{Pt}-\mathrm{TiO}_{2}$ interface sites such as edges of Pt clusters (or atoms) on $\mathrm{TiO}_{2}$. The desorption features at $300 \mathrm{~K}, 400 \mathrm{~K}$ and $500 \mathrm{~K}$ are absent in spectrum (b)

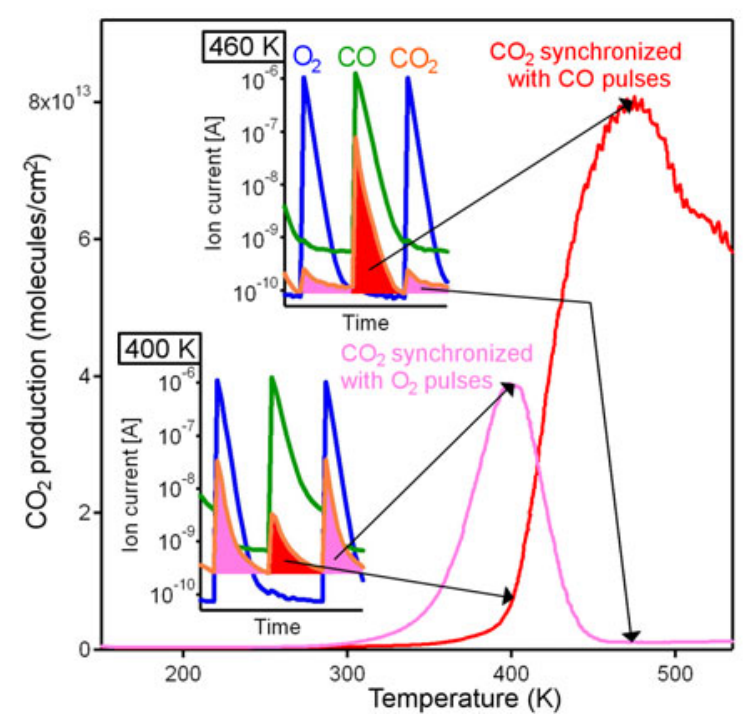

Fig. 6. (Color online) $\mathrm{CO}_{2}$ production versus temperature on $\mathrm{Pt} / \mathrm{YSZ}$ synchronized with one or the other reactant pulse in order to reveal $\mathrm{CO}$ rich and $\mathrm{O}$ rich phases. The heating rate is $0.1 \mathrm{~K} / \mathrm{s}$. As shown in the insets isotopic ${ }^{13} \mathrm{C}^{16} \mathrm{O}$ (green) and ${ }^{18} \mathrm{O}_{2}$ (blue) have been pulsed alternatingly, with a delay of $5 \mathrm{~s}$, and $\mathrm{CO}_{2}\left({ }^{13} \mathrm{C}^{16} \mathrm{O}^{18} \mathrm{O}\right.$, orange) has been measured. The integrals of the $\mathrm{CO}_{2}$ peaks are reported versus temperature in pink for the peaks synchronized with $\mathrm{O}_{2}$ pulses and in red for the peaks synchronized with $\mathrm{CO}$ pulses.

giving strong evidence that the annealed Pt clusters are encapsulated by a titania layer. This loss of $\mathrm{CO}$ adsorption sites with high binding energy is known as SMSI state $[55-57]$.

\subsection{Catalysis measurements on $\mathrm{Pt} / \mathrm{YSZ}$}

We have studied the catalytic CO oxidation on a thick Pt film on YSZ, the ex-situ preparation of which is described in reference [58]. The insets in Figure 6 show the $\mathrm{CO}_{2}\left({ }^{13} \mathrm{C}^{16} \mathrm{O}^{18} \mathrm{O}\right.$, orange) signal obtained when isotopic ${ }^{13} \mathrm{C}^{16} \mathrm{O}$ (green) and ${ }^{18} \mathrm{O}_{2}$ (blue) reactants are pulsed alternatingly on Pt/YSZ with a delay of $5 \mathrm{~s}$ between the pulses. With the heating rate of $0.1 \mathrm{~K} / \mathrm{s}$ one period of dose pulses corresponds to a temperature increase of $1 \mathrm{~K}$, and correspondingly, the insets show very narrow temperature windows, centered around $400 \mathrm{~K}$ in the lower and around $460 \mathrm{~K}$ in the upper inset. These measurements have been performed for a temperature range of 150-535 K. The $\mathrm{CO}_{2}$ signal, once synchronized with the $\mathrm{CO}$ and once with the $\mathrm{O}_{2}$ pulses, has been integrated at each peak and plotted in Figure 6 as function of temperature in absolute units using the above mentioned calibrations. Both curves have been smoothened in order to compensate the aliasing effect due to the limited QMS time resolution. Two temperature regimes of $\mathrm{CO}_{2}$ production are seen in Figure 6. Between 300 and $420 \mathrm{~K}$, the $\mathrm{CO}_{2}$ production is mainly synchronized with the $\mathrm{O}_{2}$ pulses, while 


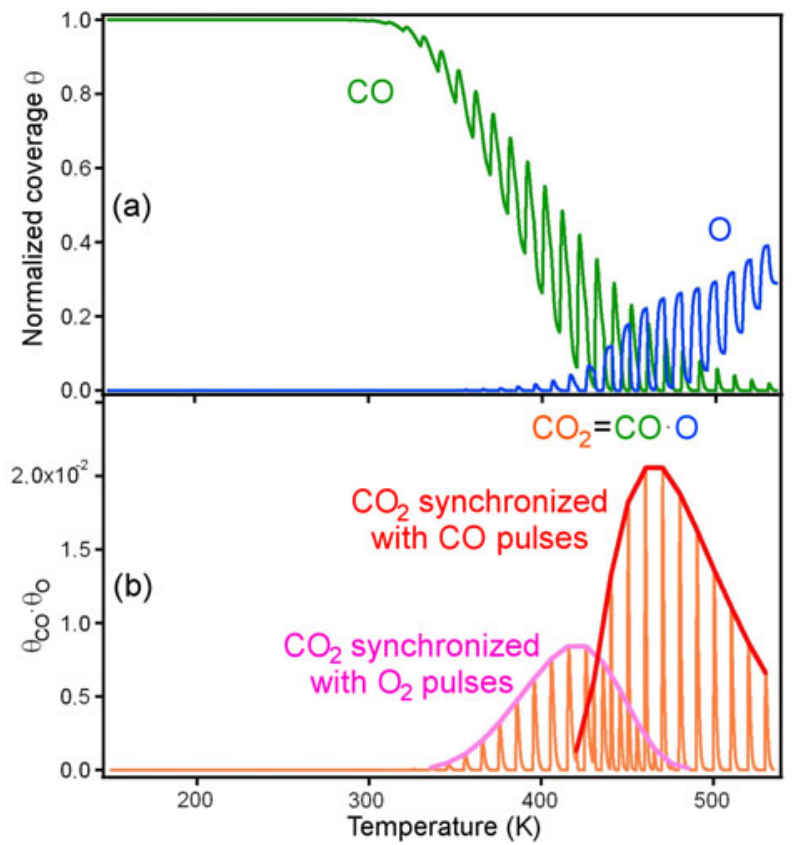

Fig. 7. (Color online) (a) Simulated $\mathrm{CO}$ and $\mathrm{O}$ coverages on a $\mathrm{Pt}$ surface as a function of temperature. (b) $\mathrm{CO}_{2}$ production calculated as the product between the simulated $\mathrm{CO}$ and $\mathrm{O}$ coverages shown in (a).

above $420 \mathrm{~K}$, the $\mathrm{CO}_{2}$ production is mainly synchronized with the $\mathrm{CO}$ pulses.

Before discussing these two regimes, we note that no important $\mathrm{CO}_{2}$ production is observed below $300 \mathrm{~K}$. At these lower temperatures the surface is saturated with $\mathrm{CO}$ and therefore no adsorption and dissociation of $\mathrm{O}_{2}$ can take place. This is known as $\mathrm{CO}$ poisoning of the catalyst (see $[4,59]$ and references therein). As the temperature increases the $\mathrm{CO}$ desorption temperature is reached and, the lifetime of adsorbed $\mathrm{CO}$ becomes comparable to the time delay between $\mathrm{CO}$ and $\mathrm{O}_{2}$ pulses. When $\mathrm{O}_{2}$ is dosed, the majority of surface sites are occupied by residual $\mathrm{CO}$ but the remaining free sites can adsorb and dissociate $\mathrm{O}_{2}$. Once $\mathrm{CO}$ and $\mathrm{O}$ are both present on the surface, the production of $\mathrm{CO}_{2}$ following the LangmuirHinshelwood mechanism becomes possible. The low temperature regime is thus characterized by a $\mathrm{CO}$ rich surface. Above $420 \mathrm{~K}$ the $\mathrm{CO}_{2}$ production synchronized with the $\mathrm{CO}$ pulses takes over. This shows that the surface becomes oxygen rich and from $460 \mathrm{~K}$ on, where the maximum $\mathrm{CO}_{2}$ production is observed, only dissociated oxygen remains adsorbed on the surface, and therefore the $\mathrm{CO}_{2}$ production is synchronized with the $\mathrm{CO}$ pulses.

In order to extract quantitative information on the reaction kinetics we performed the following simulation. The reactants are pulsed with the delay as in experiment and associated with $\mathrm{CO}$ and $\mathrm{O}$ coverages on a $\mathrm{Pt}(111)$ surface. These coverages vary with time and hence with temperature as given by the following coupled differential equations:

$$
\begin{aligned}
\frac{d \theta_{\mathrm{CO}}}{d t}= & -\nu_{\mathrm{CO}} \theta_{\mathrm{CO}} e^{-\frac{E_{\mathrm{CO}}\left(\theta_{\mathrm{CO}}\right)}{k_{B} T(t)}} \\
& +P_{\mathrm{CO}}(t)\left(1-\theta_{\mathrm{CO}}\right)-A \theta_{\mathrm{CO}} \theta_{\mathrm{O}} \\
\frac{d \theta_{\mathrm{O}}}{d t}= & -\nu_{\mathrm{O}} \theta_{\mathrm{O}}^{2} e^{-\frac{E_{\mathrm{O}}\left(\theta_{\mathrm{O}}\right)}{k_{B} T(t)}} \\
& +P_{\mathrm{O}}(t)\left(1-\theta_{\mathrm{O}}-\theta_{\mathrm{CO}}\right)^{2}-A \theta_{\mathrm{CO}} \theta_{\mathrm{O}}
\end{aligned}
$$

The first terms on the right side of equations (1) and (2) describe the desorption, where $\theta_{i}$ are the coverages, $\nu_{i}$ the attempt frequencies, and $E_{i}\left(\theta_{i}\right)$ the possibly coveragedependent adsorption energies of $\mathrm{CO}$ and $\mathrm{O}$. The second terms describe the adsorption, which is proportional to $P_{i}(t)$, which itself is proportional to the product between the pulse intensity and the sticking factor. This term is proportional to the number of free adsorption sites for $\mathrm{CO}$, and proportional to the square of this number for $\mathrm{O}_{2}$ since the adsorption is dissociative. Since adsorbed oxygen does not hinder the reaction while adsorbed $\mathrm{CO}$ does, we consider an oxygen-occupied site to be a free one for $\mathrm{CO}$ adsorption, but a $\mathrm{CO}$-occupied site is not considered to be a free site for $\mathrm{O}_{2}$ adsorption. The last terms in the two equations account for the adsorbed $\mathrm{CO}$ and $\mathrm{O}$ consumption due to the $\mathrm{CO}_{2}$ production. They are proportional to the product of the coverages and a reaction speed $A$ which is assumed to be constant. $T, t$ and $k_{B}$ are the temperature, the time, and the Boltzmann constant, respectively.

The coupled differential equations are solved numerically and the resulting coverages of $\mathrm{CO}$ and $\mathrm{O}$ are shown as a function of temperature in Figure $7 \mathrm{a}$ in green and blue, respectively. The $\mathrm{CO}$ poisoning is clearly visible at low temperatures and the CO coverage decrease starts at around $300 \mathrm{~K}$. The oxygen coverage now increases by each gas pulse but it is transformed into $\mathrm{CO}_{2}$ by residual $\mathrm{CO}$ adsorbed on the surface and by each following $\mathrm{CO}$ pulse. The CO coverage between $300 \mathrm{~K}$ and $420 \mathrm{~K}$ remains high and we call this regime CO-rich. CO desorbs much faster at higher temperatures and atomic oxygen becomes the dominant species on the surface. The $\mathrm{CO}_{2}$ production spectrum in orange in Figure $7 \mathrm{~b}$ calculated as the product between the simulated $\mathrm{CO}$ and $\mathrm{O}$ coverages agrees quantitatively with the experiment when reasonable adsorption energies, prefactors and pulse intensities are used. The values used for Figure 7 are $\nu_{\mathrm{CO}}=\nu_{\mathrm{O}_{2}}=10^{13} \mathrm{~s}^{-1}$, $E_{\mathrm{CO}}\left(\theta_{\mathrm{CO}}\right)=\left(1.22-0.25 \theta_{\mathrm{CO}}\right) \mathrm{eV}$ (the coverage dependence comes from the known dipole-dipole repulsion of $\mathrm{CO}$ ), and $E_{\mathrm{O}}=2.17 \mathrm{eV}$, both adsorption energies being in good agreement with literature data [60-62]. Figure 7b can be considered as an action spectrum which depends sensitively on the input parameters and serves as a method to determine the adsorption/desorption behavior of the reactant gases on the Pt surface.

\section{Conclusion}

A new home-built highly sensitive and selective instrument for nano-catalysis at surfaces, called sniffer, has been 
described. It is integrated in a UHV system equipped with a LT-STM and a mass-selected cluster source, enabling the direct correlation between surface morphology and catalytic properties. Two model catalysts have been studied. TDS of $\mathrm{CO}$ on $\mathrm{Pt} / \mathrm{TiO}_{2}(110)-(1 \times 1)$ shows the desorption features of $\mathrm{TiO}_{2}$ terraces, $\mathrm{Pt}$ steps and $\mathrm{Pt}$ terraces, as well as $\mathrm{Pt}-\mathrm{TiO}_{2}$ interface sites. The latter three features disappear upon annealing to $1100 \mathrm{~K}$ which is attributed to the formation of a passivating titania layer on the Pt clusters. Catalytic CO oxidation on Pt/YSZ shows two temperature regimes of $\mathrm{CO}_{2}$ production related to a $\mathrm{CO}$ rich and an $\mathrm{O}$ rich surface, and permitting deduction of the adsorption/desorption dynamics of the reactants. This is quantitatively reproduced by simulations of the reaction on a $\operatorname{Pt}(111)$ surface. These results demonstrate the operation of the sniffer and the value added by combining it with the other techniques housed in the UHV experimental setup.

This work has been supported by the Swiss National Science Foundation.

\section{References}

1. U. Heiz, A. Sanchez, S. Abbet, W.D. Schneider, J. Am. Chem. Soc. 121, 3214 (1999)

2. A. Sanchez, S. Abbet, U. Heiz, W.D. Schneider, H. Häkkinen, R. Barnett, U. Landman, J. Phys. Chem. A 103, 9573 (1999)

3. U. Heiz, F. Vanolli, A. Sanchez, W.D. Schneider, J. Am. Chem. Soc. 120, 9668 (1998)

4. S. Kunz, F.F. Schweinberger, V. Habibpour, M. Röttgen, C. Harding, M. Arenz, U. Heiz, J. Phys. Chem. C 114, $1651(2010)$

5. B. Yoon, H. Häkkinen, U. Landman, A.S. Wörz, J.M. Antonietti, S. Abbet, K. Judai, U. Heiz, Science 307, 403 (2005)

6. K. Judai, S. Abbet, A.S. Wörz, U. Heiz, C.R. Henry, J. Am. Chem. Soc. 126, 2732 (2004)

7. L.D. Socaciu, J. Hagen, T.M. Bernhardt, L. Wöste, U. Heiz, H. Häkkinen, U. Landman, J. Am. Chem. Soc. 125, 10437 (2003)

8. A.S. Wörz, K. Judai, S. Abbet, U. Heiz, J. Am. Chem. Soc. 125, 7964 (2003)

9. S. Abbet, U. Heiz, H. Häkkinen, U. Landman, Phys. Rev. Lett. 86, 5950 (2001)

10. S. Abbet, E. Riedo, H. Brune, U. Heiz, A.M. Ferrari, L. Giordano, G. Pacchioni, J. Am. Chem. Soc. 123, 6172 (2001)

11. C. Fan, T. Wu, W.E. Kaden, S.L. Anderson, Surf. Sci. 600, $461(2006)$

12. S. Lee, C. Fan, T. Wu, S.L. Anderson, Surf. Sci. 578, 5 (2005)

13. S. Lee, C. Fan, T. Wu, S.L. Anderson, J. Am. Chem. Soc. 126, $5682(2004)$

14. M. Aizawa, S. Lee, S.L. Anderson, Surf. Sci. 542, 253 (2003)

15. S. Chrétien, S.K. Buratto, H. Metiu, Curr. Opin. Solid State Mater. Sci. 11, 62 (2007)

16. X. Tong, L. Benz, P. Kemper, H. Metiu, M.T. Bowers, S.K. Buratto, J. Am. Chem. Soc. 127, 13516 (2005)
17. S. Vajda et al., Nature Mater. 8, 213 (2009)

18. S. Vajda, R. Winans, J. Elam, B. Lee, M. Pellin, S. Seifert, G. Tikhonov, N. Tomczyk, Topics Catal. 39, 161 (2006)

19. U. Heiz, F. Vanolli, L. Trento, W.D. Schneider, Rev. Sci. Instrum. 68, 1986 (1997)

20. M. Arenz, U. Landman, U. Heiz, Chem. Phys. Chem. 7, $1871(2006)$

21. K. Judai, S. Abbet, A.S. Wörz, M.A. Röttingen, U. Heiz, Int. J. Mass Spectrom. 229, 99 (2003)

22. C.J. Harding, S. Kunz, V. Habibpour, V. Teslenko, M. Arenz, U. Heiz, J. Catal. 255, 234 (2008)

23. K.J. Boyd, A. Łæpicki, M. Aizawa, S. Anderson, Nucl. Instrum. Meth. B 157, 144 (1999)

24. R. Schaub, H. Jödicke, F. Brunet, R. Monot, J. Buttet, W. Harbich, Phys. Rev. Lett. 86, 3590 (2001)

25. H. Jödicke, R. Shaub, A. Bhowmick, R. Monot, J. Buttet, W. Harbich, Rev. Sci. Instrum. 71, 2818 (2000)

26. K. Bromann, C. Felix, H. Brune, W. Harbich, R. Monot, J. Buttet, K. Kern, Science 274, 956 (1996)

27. S. Duffe, T. Irawan, M. Bieletzki, T. Richter, B. Sieben, C. Yin, B. Issendorff, M. Moseler, H. Hövel, Eur. Phys. J. D 45, 401 (2007)

28. S. Duffe, N. Gronhagen, L. Patryarcha, B. Sieben, C.R. Yin, B. von Issendorff, M. Moseler, H. Hövel, Nature Nanotechnol. 5, 335 (2010)

29. P. Kemper, A. Kolmakov, X. Tong, Y. Lilach, L. Benz, M. Manard, H. Metiu, S.K. Buratto, M.T. Bowers, Int. J. Mass Spectrom. 254, 202 (2006)

30. Y. Watanabe, N. Isomura, J. Vac. Sci. Technol. A 27, 1153 (2009)

31. G. Vandoni, C. Félix, R. Monot, J. Buttet, W. Harbich, Chem. Phys. Lett. 229, 51 (1994)

32. R. Vallotton, Ph.D. thesis, EPFL, 2009, No. 4365

33. C. Wittneven, R. Dombrowski, S.H. Pan, R. Wiesendanger, Rev. Sci. Instrum. 68, 3806 (1997)

34. S.H. Pan, E.W. Hudson, J.C. Davis, Rev. Sci. Instrum. 70, 1459 (1999)

35. S. Bonanni, K. Aït-Mansour, H. Brune, W. Harbich, ACS Catal. 1, 385 (2011)

36. M.B. Hugenschmidt, L. Gamble, C.T. Campbell, Surf. Sci. 302, 329 (1994)

37. D. Brinkley, M. Dietrich, T. Engel, P. Farrall, G. Gantner, A. Schafer, A. Szuchmacher, Surf. Sci. 395, 292 (1998)

38. M.A. Henderson, Surf. Sci. 319, 315 (1994)

39. Z. Dohnálek, J. Kim, O. Bondarchuk, J.M. White, B.D. Kay, J. Phys. Chem. B 110, 6229 (2006)

40. I. Horcas, R. Fernández, J.M. Gómez-Rodríguez, J. Colchero, J. Gómez-Herrero, A.M. Baro, Rev. Sci. Instrum. 78, 013705 (2007)

41. U. Diebold, Surf. Sci. Rep. 48, 53 (2002), and references therein

42. S. Wendt et al., Science 320, 1755 (2008)

43. C.M. Yim, C.L. Pang, G. Thornton, Phys. Rev. Lett. 104, $036806(2010)$

44. Z. Zhang, O. Bondarchuk, B.D. Kay, J.M. White, Z. Dohnálek, J. Phys. Chem. B 110, 21840 (2006)

45. S. Wendt et al., Surf. Sci. 598, 226 (2005)

46. S.C. Li, Z. Zhang, D. Sheppard, B.D. Kay, J.M. White, Y. Du, I. Lyubinetsky, G. Henkelman, Z.J. Dohnálek, J. Am. Chem. Soc. 130, 9080 (2008)

47. Z. Zhang, J. Lee, J.J.T. Yates, R. Bechstein, E. Lira, J.O. Hansen, S. Wendt, F. Besenbacher, J. Phys. Chem. C 114, 3059 (2010) 
48. F. Pesty, H.P. Steinrück, T. Madey, Surf. Sci. 339, 83 (1995)

49. O. Dulub, W. Hebemstreit, U. Diebold, Phys. Rev. Lett. 84, 3646 (2000)

50. F. Sedona, G.A. Rizzi, S. Agnoli, J.X. Llabrés i Xamena, A. Papageorgiou, D. Ostermann, M. Sambi, P. Finetti, K. Schierbaum, G. Granozzi, J. Phys. Chem. B 109, 24411 (2005)

51. V.E. Henrich, G. Dresselhaus, H.J. Zeiger, Phys. Rev. Lett. 36, 1335 (1967)

52. A. Linsebigler, G. Lu, J.J.T. Yates, J. Chem. Phys. 103, $9438(1995)$

53. Z.H. Qin, M. Lewandowski, Y.N. Sun, S. Shaikhutdinov, H.J. Freund, J. Phys. Chem. C 112, 10209 (2008)
54. M.J. Lundwall, S.M. McClure, D.W. Goodman, J. Phys. Chem. C 114, 7904 (2010)

55. S.J. Tauster, S.C. Fung, R.L. Garten, J. Am. Chem. Soc. 100, 170 (1978)

56. S.J. Tauster, Acc. Chem. Res. 20, 389 (1987)

57. G.L. Haller, D.E. Resasco, Adv. Catal. 36, 173 (1989)

58. S. Souentie, C. Xia, C. Falgairette, Y.D. Li, C. Comninellis, Electrochem. Comm. 12, 323 (2010)

59. R.A. Shigeishi, D.A. King, Surf. Sci. 75, L397 (1978)

60. A. Winkler, X. Guo, H.R. Siddiqui, P.L. Hagans, J.J.T. Yates, Surf. Sci. 201, 419 (1988)

61. B. Shan, Y. Zhao, J. Hyun, N. Kapur, J.B. Nicholas, K. Cho, J. Phys. Chem. C 113, 6088 (2009)

62. L.K. Verheij, J. Lux, A.B. Anton, B. Poelsema, G. Comsa, Surf. Sci. 182, 390 (1987) 